\title{
Cost-Efficient Transition to Clean Energy Transportation Services:
}

\author{
Stephen Comello \\ Stanford Graduate School of Business \\ scomello@stanford.edu \\ Gunther Glenk \\ School of Business, University of Mannheim \\ glenk@uni-mannheim.de \\ Stefan Reichelstein \\ School of Business, University of Mannheim, \\ Stanford Graduate School of Business \\ reichelstein@uni-mannheim.de
}

June 2020

\footnotetext{
*We received helpful suggestions from Amadeus Bach, Felix Baumgarte, Stefanie Burgahn, Veronika Grimm and colleagues at the University of Mannheim and Stanford University. The cost estimates reported in this paper were made available to us by the Department of Transportation at Stanford University. We thank Brian Shaw for supporting our data collection effort; we also express our particular appreciation to Brian Jackson for his continued willingness to guide us through the details of Stanford's bus operation. Carlos Manuel Ciudad-Real provided excellent research assistance. Finally, we acknowledge financial support through DFG grant TRR 266.
} 


\begin{abstract}
Comprehensive global decarbonization will require that transportation services cease to rely on fossil fuels. Here we develop a generic life-cycle cost model to address two closely related questions central to the emergence of sustainable transportation: (i) the utilization rates (hours of operation) that rank-order alternative drivetrains in terms of their cost, and (ii) the cost-efficient share of clean energy drivetrains in a vehicle fleet of competing drivetrains. Calibrating our model framework in the context of urban transit buses, we examine how the comparison between diesel and battery-electric buses varies with the specifics of the duty cycle (route). We find that even for less favorable duty cycles, battery-electric buses will entail lower life-cycle costs once utilization rates exceed $20 \%$ of the annual hours. Yet, the current economics of that particular application still calls for a one-third share of diesel drivetrains in a cost-efficient fleet.
\end{abstract}

Keywords: clean energy vehicles, transportation services, life-cycle cost, fleet optimization 


\section{Introduction}

The global quest for energy decarbonization is increasingly focused on the transportation sector $^{1}$. The impending climate crisis, in combination with concerns about local air pollution, provide a growing impetus to replace internal combustion engines with zero-emission drivetrains ${ }^{5 / 6}$. Accordingly, clean energy transportation has the potential to make substantial progress on at least three of the United Nations' Sustainable Development Goals (SDG): improved health (SDG 3), access to sustainable energy (SDG 7), and immediate action to combat climate change (SDG 13) $7+\frac{7}{9}$.

The most economical transition to clean energy drivetrains, e.g., battery-power or hydrogen, providing either passenger or cargo transportation services remains a topic of intense debate $^{10}$.12. The central question addressed in this paper is how a fleet operator should combine alternative drivetrains with different environmental and economic characteristics so as to meet a given transportation service profile in a cost efficient manner. This question has parallels to the task of combining alternative power generation technologies, especially fossil fuel-based versus renewable power plants, to meet a given electricity load profile ${ }^{13 / 14}$.

Our model framework for identifying cost-efficient vehicle fleets relies on a cost metric called the Levelized Cost per X-mile (LCXM). It reflects the life-cycle cost per unit of a transportation service, such as a ton- or passenger-mile delivered, and extends, as discussed in detail in the next section, the Total Cost of Ownership (TCO), a metric that has been widely used in transportation studies $\frac{15}{17}$. Our model is predicated on the notion that operating costs are driven by the hours of vehicle operation. This time-based approach allows a planner to capture not only distance traveled but also other duty cycle characteristics like vehicle speed and stop frequency, all of which have differential cost implications $\frac{18 \mid 19}{19}$. The LCXM metric yields the cut-off point in terms of annual operating hours that make one drivetrain more economical than another. These cut-off points, in turn, provide the decision criterion for choosing the cost efficient shares of alternative drivetrains in a fleet that is to meet a given demand schedule or load profile.

We calibrate and apply our model framework in the context of urban transit buses. Relying on recent data from Stanford University's transportation department, we specifically contrast the life-cycle cost of battery-electric buses with that of diesel buses. While the former entail a substantially higher acquisition cost, they also result in a lower life-cycle cost compared to diesel-powered buses, provided the annual utilization rate is at least around 
1,300 hours, with the exact cut-off depending on the characteristics of the particular route served. As a reference point, the average annual utilization of transit buses in the U.S. amounts to 2,508 hours 20 .

In the context of Stanford's load profile for bus services, we find that the share of electric vehicles in a cost-efficient bus fleet varies between one and two thirds, depending on the routes to be served. The overall implication is that while ongoing trends favor increasing reliance on electric buses within a fleet, conventional drivetrains remain part of a cost-efficient fleet in the California environment for now. We conclude with a sensitivity analysis that highlights the dependence of our findings on key model parameters pertaining to public policy and general economic trends.

\section{Cost-Efficient Vehicle Fleets}

We begin with a unit cost measure that is a direct analogue of the familiar Levelized Cost of Electricity (LCOE). This metric serves as the relevant benchmark for comparing the cost of alternative power generation sources, such as natural gas versus solar PV. Expressed in dollars per kilowatt hour $(\mathrm{kWh})$, the LCOE is conceptualized as the average unit revenue that an equity investor would require for all kilowatt hours produced to break-even on a particular investment 21 . This unit revenue must cover all operating expenses, repay the project debt, and attain an appropriate return for equity investors $\frac{22123}{\text {. }}$

For a generic transportation service that carries physical objects across locations, our measure of output will generally be 'X-miles'. In the context of cargo transports, this measure frequently becomes ton-miles, i.e., if on average $z$ tons of cargo are transported for $y$ miles, the vehicle delivers $z \cdot y$ ton-miles. Similarly, in the context of passenger travel, the corresponding measure could be passenger-miles. For passenger cars, the appropriate measure may simply be miles if the focus is on transporting only the driver of the vehicle.

Our model is predicated on the notion that the service delivered by the vehicle and the operational costs incurred are driven by the total time the vehicle is in operation. For a given $T$-year planning horizon, we denote by $\vec{h} \equiv\left(h_{1}, \ldots, h_{T}\right)$ the usage profile of a vehicle, where $0 \leq h_{i} \leq 8,760$ is the utilization in hours of operation in year $i$ (a list of symbols and acronyms is provided in Supplementary Table 1). The number of miles traveled in year $i$ is then given by the average velocity in miles/hour, $a(\theta)$, multiplied with $h_{i}$. Velocity depends on the duty cycle, $\theta$, a multi-dimensional parameter that captures the relevant performance 
requirements in a specific transportation context. For transit buses, for instance, the duty cycle reflects the specifics of the route, including the number of bus stops per mile, the ambient temperature, and the topography of the route.

The number of passengers or tons of cargo transported in any given year is also determined by the utilization in that year. Allowing for the possibility of a non-linear relation, we let the function $b_{i}\left(h_{i} \mid \theta\right)$ represent the average number of passengers or tons transported if the vehicle travels $a(\theta) \cdot h_{i}$ miles in year $i$. The total number of X-miles then becomes:

$$
X_{i}\left(h_{i} \mid \theta\right)=b_{i}\left(h_{i} \mid \theta\right) \cdot a(\theta) \cdot h_{i}
$$

Turning to cost components, let $v$ denote the initial acquisition expenditure for the vehicle. At the end of its useful life, the vehicle may yield a salvage value $\lambda \cdot v$, with $0<\lambda<1$. In terms of annual operating costs, we distinguish between variable and fixed costs in year $i$. The variable component, $w_{i}\left(h_{i} \mid \theta\right)$, varies with the hours of operation in year $i$. Fixed costs, $F_{i}(\theta)$, are by definition usage-independent. Applicable examples for variable operating costs include fuel, spare parts, and the prorated salary for the driver. In contrast, insurance, registration, and certain maintenance activities reflect fixed costs.

Aggregation of the different cost components into a single unit cost number requires a "levelization" factor given by the discounted number of X-miles that the vehicle travels over its useful life. Let $r$ denote the applicable cost of capital that investors require for a project, with $\gamma=\frac{1}{1+r}$ denoting the corresponding discount factor. We then define the levelization factor in terms of discounted future X-miles as:

$$
Y(\vec{h} \mid \theta)=\sum_{i=1}^{T} X_{i}\left(h_{i} \mid \theta\right) \cdot \gamma^{i}
$$

A final cost category stems from corporate income taxes and a depreciation tax shield that a firm or individual may be subject to. As shown in Methods, this cost category can be summarized, including the potential salvage value, in a factor $\Delta$ that adjusts the acquisition cost of the vehicle. Overall, the levelized cost per X-mile is then defined as the sum of three components:

$$
L C X M(\vec{h} \mid \theta)=w(\vec{h} \mid \theta)+f(\vec{h} \mid \theta)+c(\vec{h} \mid \theta) \cdot \Delta
$$


where:

$$
c(\vec{h} \mid \theta) \equiv \frac{v}{Y(\vec{h} \mid \theta)}, \quad w(\vec{h} \mid \theta) \equiv \frac{\sum_{i=1}^{T} w_{i}\left(h_{i} \mid \theta\right) \cdot \gamma^{i}}{Y(\vec{h} \mid \theta)}, \quad f(\vec{h} \mid \theta) \equiv \frac{\sum_{i=1}^{T} F_{i} \cdot \gamma^{i}}{Y(\vec{h} \mid \theta)}
$$

In Methods, we formally establish that the LCXM metric, as defined in (1), does satisfy our break-even criterion that investment in a vehicle has zero net-present value if the revenue per X-mile delivered is exactly equal to the LCXM.

The LCXM metric yields an immediate cut-off point in terms of utilization that makes one drivetrain preferable to another in terms of life-cycle cost. For simplicity, suppose that the variable cost, $w_{i}(\cdot)$, per hour of operation is constant such that $w_{2}>w_{1}$. If drivetrain 1 involves a higher acquisition cost than drivetrain 2, we refer to the former as 'baseload' and the latter (drivetrain 2) as the 'peaker'. The baseload drivetrain will then be more cost effective if in each year $i$ the utilization rate $h_{i}$ exceeds the cut-off utilization rate $h^{*}$, given as the unique value that equates the two levelized cost curves, that is:

$$
L C X M_{1}\left(h^{*}, \ldots, h^{*} \mid \theta\right)=L C X M_{2}\left(h^{*}, \ldots, h^{*} \mid \theta\right) .
$$

Conversely, the peaker drivetrain will dominate for consistently low utilization rates $h_{i}<h^{*}$. Depending on the specific cost parameters, it is, of course, possible that $h^{*}$ falls outside the range $[0,8760]$, in which case the peaker entails lower life-cycle cost irrespective of the actual utilization rates.

Consider now a service provider that chooses a vehicle fleet composed of multiple drivetrains. Initially, we suppose that $L(t)$ represents the load profile of vehicles required to operate during the $t$-th hour of every day of the year, in each of the next $T$ years on the same duty cycle $\theta$. Suppose the service provider seeks to minimize the acquisition- and ongoing operating costs of two alternative drivetrains. Let $k_{u}$ denote the number of vehicles of type $u$. It will be convenient to first ignore the integer constraint on vehicles. Suppose that the maximum value of $L(t)$ on $[0,24]$ is $k_{+}$, and that $L(\cdot)$ can be uniformly approximated by a polynomial function on the interval $[0,24]$ (Weierstrass Theorem). Thus $k_{1}+k_{2} \geq k_{+}$. Finally, let $D(k)$ denote the total amount of time in $[0,24]$ during which at least $k$ vehicles 
must be in operation according to $L(\cdot)$. Formally,

$$
D(k) \equiv\|\{t \in[0,24] \mid L(t) \geq k\}\|,
$$

where $\|\cdot\|$ denotes the total length of the intervals for which $L(t) \geq k$. Since $L(\cdot)$ can be described by a polynomial, there are at most finitely many such intervals. By construction, $D(\cdot)$ is continuous and decreasing in $k$. Furthermore, if $L(\cdot)$ attains its maximum at a unique point in time, the function $D(\cdot)$ assumes all values between zero and 24 . Consider two drivetrains whose levelized cost curves, $\operatorname{LCX} M_{1}(\cdot)$ and $\operatorname{LCX} M_{2}(\cdot)$, intersect at $\left(h^{*}, \ldots, h^{*}\right)$ with $h^{*} \in[0,8760]$. As demonstrated formally in Methods, given the daily load profile $L(t)$, the cost-minimizing number of baseload drivetrains, $k_{1}^{*}$, is given as the solution to the following equation:

$$
365 \cdot D\left(k_{1}^{*}\right)=h^{*}
$$

The intuition for this result is that in order for the total cost associated with the fleet operation to be minimized, the 'marginal' baseload vehicle (drivetrain 1) must operate for exactly $\frac{h^{*}}{365}$ hours per day. Otherwise the total life-cycle cost could be lowered by either replacing this last vehicle by a peaker or expanding the number of baseload vehicles. Since $k_{1}^{*}$ will generally not be an integer, the actual cost-minimizing number of baseload drivetrains will be one of the two integers adjacent to the $k_{1}^{*}$ identified in (4). Furthermore, the overall LCXM associated with the load profile $L(\cdot)$ is a convex combination of the two individual LCXMs.

The preceding framework is readily extended to settings where each day has its own distinct load profile $L_{j}(\cdot)$, with $1 \leq j \leq 365$. We suppose each $L_{j}(\cdot)$ satisfies the same technical conditions as $L(\cdot)$ above, and denote by $D_{j}(\cdot)$ the analogue of the function $D(\cdot)$ in (3) corresponding to $L_{j}(\cdot)$. The cost-minimizing number of baseload drivetrains, $k_{1}^{*}$, is then given by (see Methods):

$$
\sum_{j=1}^{365} D_{j}\left(k_{1}^{*}\right)=h^{*}
$$

Our unit cost concept of the LCXM is related to the Total Cost of Ownership (TCO). The latter captures the total discounted cost of acquiring, operating, and selling a vehicle. It thus corresponds to the numerator in expressions (1) and (2). TCO has been employed in the literature to compare the overall cost of alternative drivetrains at the vehicle level ${ }^{[15}\left[\frac{17}{1}\right.$, and in connection with fleets ${ }^{2426}$, including specifically bus fleets ${ }^{1112}$. 
Our conceptualization of the life cycle cost of transportation services is in the tradition of time-driven activity based costing systems, a construct that has proven useful in multiple industries, including energy systems and health care ${ }^{19127}$. This time-driven approach enables us to capture the multi-dimensional features of a particular duty cycle, including vehicle speed, distance traveled and stop frequency. As shown in the next section, the combination of these has first-order effects for the cost competitiveness of alternative drivetrains and the composition of cost-effective vehicle fleets. Thus, the LCXM concept provides a unified framework for examining the (i) cost competitiveness of individual vehicles, (ii) optimal mix of alternative drivetrains in a fleet, (iii) efficient dispatch of alternative drivetrains, and (iv) effect of multi-dimensionality of the duty cycle on cost-efficient vehicle fleets.

\section{Application: Transit Bus Fleets}

We now apply the preceding framework to Stanford University's bus service known as Marguerite. Like a municipal bus service, Marguerite interconnects the university campus and the surrounding community via multiple routes, operating daily at varying levels of capacity utilization with peaks during weekday mornings and afternoons. The majority of the service is run with transit buses (see Supplementary Table 2). Beginning in 2014, the university has gradually replaced diesel-powered with battery-electric buses.

To compare the life-cycle cost of the two drivetrains, our calculations focus on the duty cycles of two distinct routes, referred to as Route A and B. They reflect opposite ends of the range of duty cycles operated by Marguerite, with the number of bus stops per mile as 1.1 and 2.7 and average velocity (in miles per hour) as 7.4 and 3.0 for Route A and Route B, respectively. Since topography and ambient temperature of all campus routes are virtually identical, Routes A and B generally yield corner solutions for all routes operated by Marguerite.

Our analysis relies on the records of Stanford's transportation department for recent cost and operational data (details provided in Methods). Table 1 shows average values for the main life-cycle cost components. The net acquisition cost represents the initial purchasing price minus the salvage value and, for electric buses, a capital incentive of $\$ 100,000$ granted by the California Air Resources Board 28 . The variable cost comprises fuel costs and variable maintenance costs but excludes the salary of drivers, which is the same across drivetrains.

Considering the variable costs in Table 1, one might expect that more stops per mile 
Table 1: Main cost parameters (in 2019 \$US).

\begin{tabular}{lcc}
\hline & Diesel & Electric \\
\hline Variable cost per hour (Route A) & $\$ 26.25$ & $\$ 2.02$ \\
Variable cost per hour (Route B) & $\$ 16.79$ & $\$ 4.77$ \\
Fixed cost per year & $\$ 5,054$ & $\$ 5,913$ \\
Net acquisition cost & $\$ 425,189$ & $\$ 631,300$ \\
Useful lifetime & 12 years & 12 years \\
Cost of capital & $5.00 \%$ & $5.00 \%$ \\
\hline
\end{tabular}

(Route B) increases the variable cost of both drivetrains and especially that of diesel buses whose fuel consumption is more sensitive to frequent stops. This intuition is, however, misleading for diesel buses in the context of Marguerite. The increased fuel cost per mile of diesel buses for Route B is outweighed by a lower average velocity such that the fuel cost per hour of operation decreases. For electric buses, in contrast, this intuition is confirmed in Table 1. Moving from Route A to B, the fuel cost per hour of operation decreases, yet variable maintenance costs increase with the number of stops per mile for both drivetrains. The latter effect is dominant for electric buses.

Figure 1 depicts the levelized cost curves per passenger-mile (LCPM) for both drivetrains by route, where there is a unique critical utilization, $h^{*}$, beyond which electric buses entail lower life cycle cost. These values amount to 996 hours for Route A and 2,006 hours for Route $\mathrm{B}$, marked by the solid vertical lines in Figure 1. The explanation for the counterintuitive finding that the critical utilization rate is larger for Route B than for Route A is given by the above observation: the variable cost per hour of diesel buses is lower for Route $\mathrm{B}$, because the buses travel fewer miles per hour when there are more stops per mile. The critical utilization for the average duty cycle (number of stops per mile) of the entire Marguerite system amounts to 1,329 hours; see Methods for details.

The operational records of Stanford University show that Route A is almost exclusively served by electric buses, while the opposite holds for Route B. The average annual utilization factors amount to 1,434 hours and 1,453 hours, respectively. For these utilization factors, Figure 1 shows that the LCPM of electric buses is lower than that of diesel buses on Route A, while the opposite pattern applies on Route B. The university's reliance on these two drivetrains for the two routes thus appears consistent with the goal of minimizing the lifecycle cost of transportation services provided. For further reference, the average annual utilization of transit buses in the U.S. amounts to 2,508 hours ${ }^{20}$. Such high utilization rates 

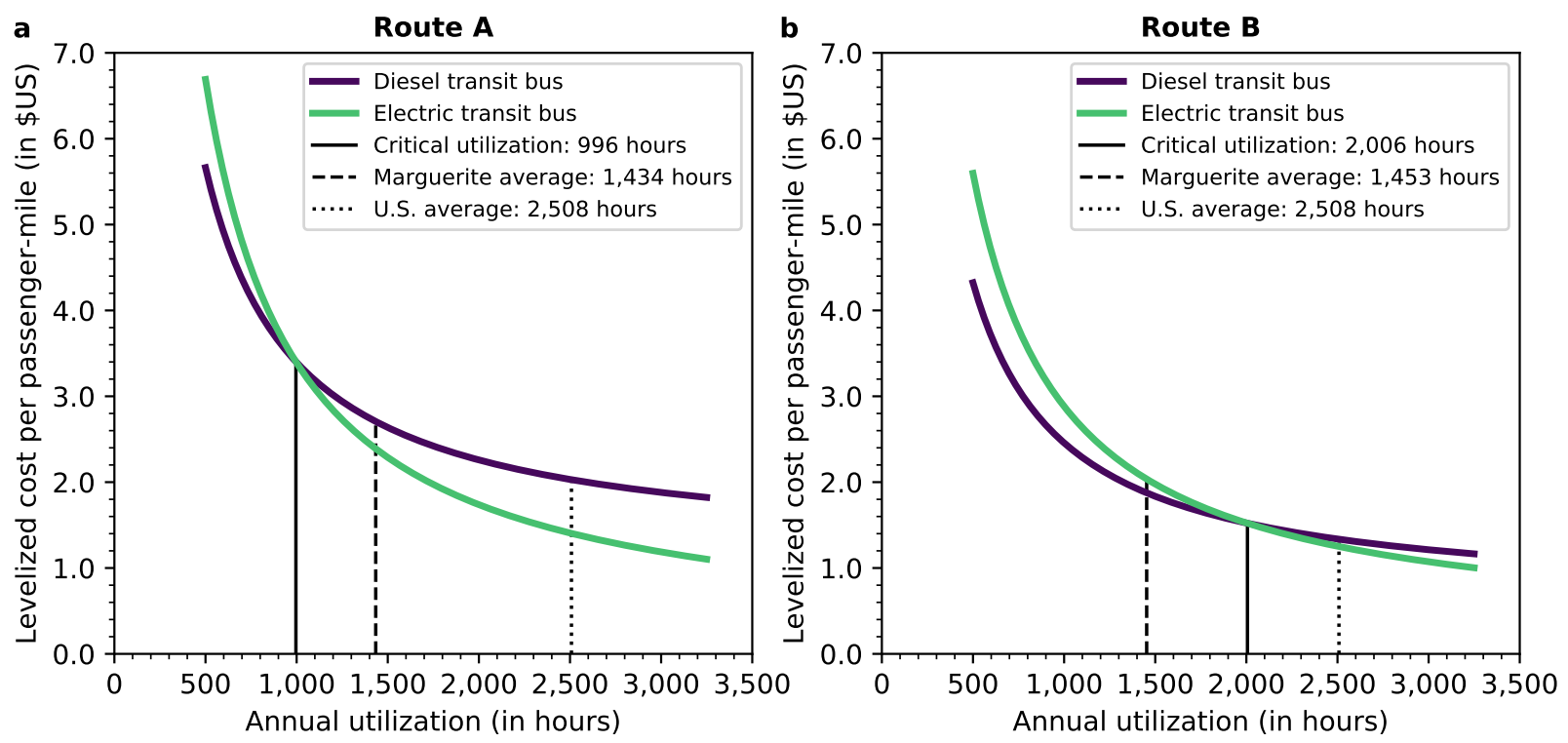

Figure 1: Levelized cost per passenger-mile. a,b, This figure shows the levelized cost per passenger-mile of diesel and electric transit buses for (a) Route A and (b) Route B.

would give electric buses a cost advantage on both routes, as shown in Figure 1.

Figure 2 depicts the daily load profiles of buses operating on the Stanford campus. If hypothetically all Marguerite buses were to run on Route A, the efficient number of diesel and electric buses would amount to 7 and 22, respectively. The corresponding values for Route B are 18 and 11. Since the functions $D_{j}(\cdot)$ are decreasing in $k_{1}$, the efficient number of electric buses for Route B is smaller than on Route A, as the corresponding critical utilization factor $h^{*}$ is larger for Route B (see Figure 1). Though the proportion of the two competing drivetrains within the fleet differ significantly for Routes A and B, diesel buses will be dispatched only within the periods corresponding to peak demand.

If the number of stops per mile is taken to be the average of all routes served by Marguerite and all buses were to serve that average route, the optimal number of diesel and electric buses would be 11 and 18. For this scenario, electric buses would be operating as baseload capacity for more than the respective $h^{*}$ hours per year, whereas each of the diesel buses would be operating as peakers for less than that. An insight from our analytical framework is that it will generally be efficient to have a mix of baseload and peaker vehicles, unless the underlying load profile assumes an 'extreme' shape. Specifically, even if all campus routes were to correspond to the characteristics of Route B, which tends to favor diesel buses, a planner would still want to procure 11 electric buses out of a total of 29 . That share would, 

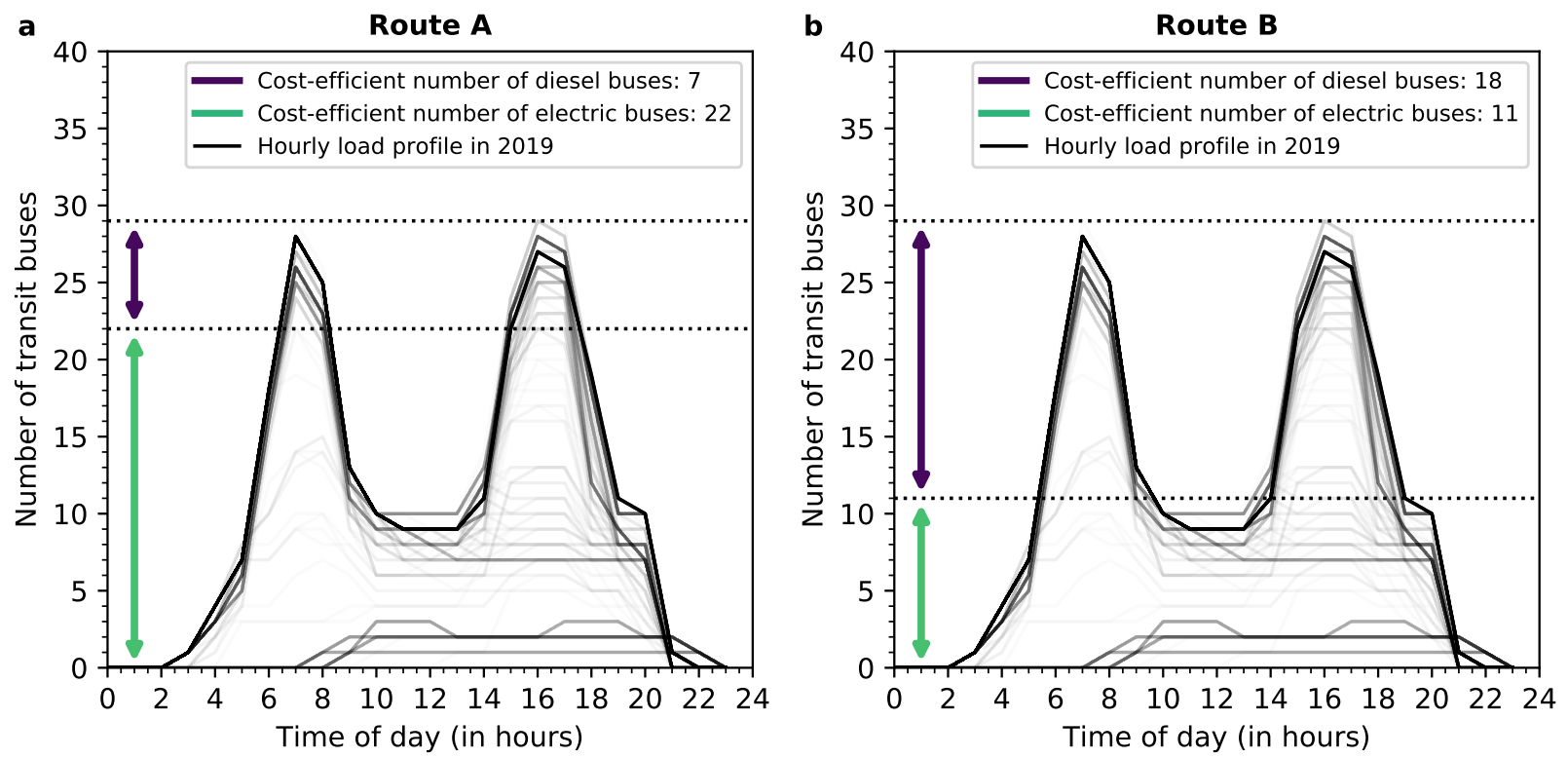

Figure 2: Cost-efficient vehicle fleets. a,b, This figure shows the cost-efficient number of diesel and electric transit buses for the hourly load profile of Marguerite in 2019 if hypothetically all routes exhibited a duty cycle of either (a) Route A and (b) Route B. It also shows the efficient dispatch sequence of the fleet, with diesel buses allocated to serving only within the peak "rush-hour" demand periods, and electric buses serving the remainder. The load profile depicted here is an overlay of the hourly profile for individual days in 2019. The more the daily profiles overlap, the darker is the shade of gray. The upper twin peaks represent load profiles on weekdays, while the lower twin peaks display the profile for weekend days.

of course, be even larger if the load profile in Figure 2 were to be less "peaky" and replaced by a more uniform service schedule.

Our model of fleet optimization has ignored requirements for backup capacity due to the need to accommodate irregular events on campus and the possibility of unscheduled vehicle maintenance. In fact, Stanford University currently maintains 10 transit buses over and above the annual peak demand of 29 scheduled buses. That observation is consistent with the utilization rate on both routes being significantly below the U.S. average. At the same time, given that the university had acquired 29 electric buses in 2019 , it will be advantageous to reduce reliance on diesel buses to the largest extent possible due to their higher operating costs. 


\section{Discussion}

Since our numerical calibration of the life-cycle cost of transit buses is based on a single university service operator, it is essential to check the sensitivity of our findings to changes in the key input variables. Specifically, the graphs in Figure 3 focus on the sensitivity of

the critical utilization rate, i.e., $\frac{h^{*}}{8760}$, as derived in Figure 1 and the efficient share of electric buses, i.e., $\frac{k_{1}^{*}}{29}$, as derived in Figure 2. For consistency, the comparisons focus on the same two routes so as to illustrate the impact of alternative duty cycles.

The purple lines in Figure 3 indicate that both dependent variables $\left(h^{*}\right.$ and $\left.k_{1}^{*}\right)$ are relatively insensitive to changes in the variable cost of electric buses, as variable costs constitute only a minor share of the overall life-cycle cost of electric buses. In contrast, the blue lines in Figure 3 show that our dependent variables are sensitive to changes in the variable cost of diesel buses, with diesel fuel constituting a significant share of that variable cost (see Methods for details). The cost of diesel fuel is likely to vary over time and across geographic regions, possibly because diesel fuel may become subject to $\mathrm{CO}_{2}$ emission charges in some jurisdictions. Quantifying the overall effect, the blue lines in Figure 3 show that a 10\% increase in the variable cost of diesel buses will decrease the critical utilization rate by about 10-15\%, depending on the route. The corresponding impact on the efficient share of electric buses would be more pronounced on Route B, and result in an increase of $k_{1}^{*}$ by about $10 \%$.

One would expect any increases in the cost of capital to weaken the competitive position of electric buses, that is $h^{*}$ to increase and $k_{1}^{*}$ to decrease. While the LCPM of both drivetrains will increase, a larger cost of capital should have a more pronounced effect on the more capital intensive drivetrain, i.e., electric vehicles. A similar observation emerges in connection with capital intensive renewable energy in comparison to fossil fuel power plants 29 . The yellow lines in Figure 3 confirm this intuition, though the changes in the dependent variables turn out to be relatively minor on both routes, and for both variables. Specifically, the critical utilization rate increases almost linearly at the modest rate of $3 \%$ for every $10 \%$ increase in the cost of capital.

Recent advances in lithium-ion battery technology have significantly lowered the price of lithium-ion battery packs which, in turn, comprise a significant share of the net acquisition cost of battery electric buses. Numerous recent studies point to sustained cost reductions in the future along the trajectory of a classic learning curve ${ }^{3130[31}$. An additional development that is forecast to lower the net acquisition cost of battery electric buses is the emergence 

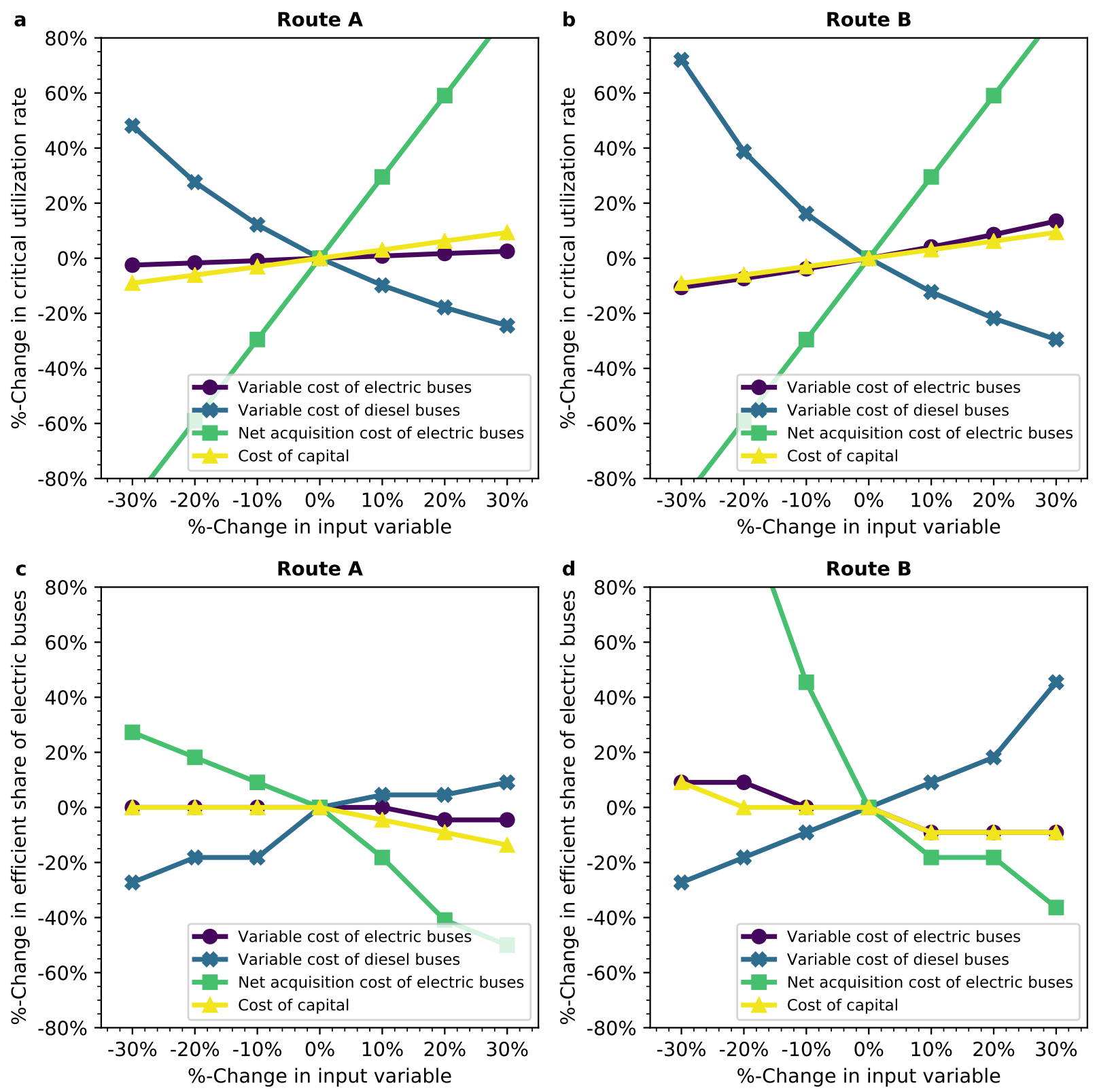

Figure 3: Sensitivity analysis. a,b,c,d This figure shows the sensitivity of the critical utilization rate on (a) Route A and (b) Route B, as well as the sensitivity of the efficient share of electric buses on (c) Route A and (d) Route B to four different input variables

of a market for "second-life" battery applications ${ }^{32133}$, once the degradation of the battery packs makes them no longer suitable for transportation services. In the context of our model this would increase the salvage value with a corresponding decrease in the net acquisition cost of electric buses. The green lines in Figure 3 confirm that the critical utilization rate is highly sensitive to increases in the net acquisition cost of electric buses. On either route, a 
$10 \%$ change in the net acquisition cost results in approximately a 30\% change in $h^{*}$.

Naturally, the efficient share of electric vehicles is decreasing in the net acquisition cost of electric vehicles. These decreases occur at a lower rate on Route A (Figure 3r) compared to Route B (Figure 3d) which exhibits a larger difference in the hourly operating costs of the two drivetrains. From a public policy perspective, we find that without the current $\$ 100,000$ capital subsidy made available to electric buses by the California Air Resource Board (CARB), the efficient share of electric vehicles in the Stanford fleet would decrease by about $25 \%$. However, if the net acquisition cost of electric vehicles were to drop by $40 \%$, then on both routes an all electric bus fleet would be cost-minimizing. Based on current

price trajectories for lithium-ion battery packs ${ }^{30131}$ and conservatively estimating that such packs constitute $30 \%$ of the net acquisition cost, this scenario should emerge no later than the year 2025 .

\section{Concluding Remarks}

This paper has examined a time-driven life-cycle cost model for transportation services. Our metric identifies the critical utilization rate that ranks alternative drivetrains in terms of their life-cycle cost. This critical utilization rate is shown to provide the decision criterion for the efficient mix of alternative drivetrains in a vehicle fleet. We calibrate this metric in the context of Stanford University's bus service as a case in point. While the current numbers still point to a significant role for diesel buses, continued improvements in electric drivetrains could change this conclusion within the next five years, consistent with the goals articulated in SDG 13.

Our framework is applicable in future research for a range of transportation contexts, including passenger and cargo transports by road, water and air. In the context of passenger road vehicles, the recent advances in mobility-as-a-service suggest that the traditional ownership model will increasingly be replaced by fleet ownership ${ }^{34}$ 36. End-users will then be able to meet their transportation needs through spot market service arrangements with fleet operators. This technological development and the wider adoption of clean energy vehicles are likely to reinforce each other on account of higher utilization rates associated with vehicle sharing and the comparatively lower operating costs of clean energy vehicles $\frac{37}{40}$. 


\section{Methods}

Economic Model. We first complete the description of the model and then validate the formal claims in the main text. The tax factor, $\Delta$, depends on both the applicable income tax rate, denoted by $\alpha$, as well as the allowable depreciation schedule for tax purposes. That schedule is denoted by $\left\{d_{t}\right\}_{t=1}^{T}$, such that $d_{t} \geq 0$ and $\sum_{t} d_{t}=1$, and determines how the initial investment is amortized for tax purposes over time. The overall effect of income taxes can be summarized by:

$$
\Delta=\frac{1-\alpha \cdot\left[\sum_{t=0}^{T} d_{t} \cdot \gamma^{t}\right]}{1-\alpha}-\lambda \cdot \gamma^{T} .
$$

If $\alpha=0$, as will be the case for a non-profit organization like Stanford University, the tax factor reduces to $\Delta=1-\lambda \cdot \gamma^{T}$.

Claim 1. For a given duty cycle $\theta$ and usage profile $\vec{h}$, the $\operatorname{LCX} M(\vec{h} \mid \theta)$ in (1) is the break-even price per $X$-mile.

Proof: Suppose every X-mile attains a revenue of $p$. For a given duty cycle $\theta$ and usage profile $\vec{h}$, we demonstrate that the investment breaks even whenever $p=L C X M(\vec{h} \mid \theta)$. In year $i$, the operating revenue is given by:

$$
\operatorname{Rev}_{i}\left(h_{i}\right)=X_{i}\left(h_{i} \mid \theta\right) \cdot p=b_{i}\left(h_{i} \mid \theta\right) \cdot a(\theta) \cdot h_{i} \cdot p .
$$

The overall pre-tax cash flow in year $i$ will be represented by $C F L_{i}^{o}$. It comprises operating revenues and operating costs:

$$
C F L_{i}^{o}\left(h_{i} \mid \theta\right)=X_{i}\left(h_{i} \mid \theta\right) \cdot p-w_{i}\left(h_{i} \mid \theta\right)-F_{i}\left(h_{i} \mid \theta\right) .
$$

The firm's taxable income in year $i$ is given by:

$$
I_{i}\left(h_{i} \mid \theta\right)=X_{i}\left(h_{i} \mid \theta\right) \cdot p-w_{i}\left(h_{i} \mid \theta\right)-F_{i}\left(h_{i} \mid \theta\right)-v \cdot d_{i} .
$$

The present value of all after-tax cash flows is therefore given by:

$$
\sum_{i=1}^{T}\left[C F L_{i}^{o}\left(h_{i} \mid \theta\right)-\alpha \cdot I_{i}\left(h_{i} \mid \theta\right)\right] \cdot \gamma^{i}-v+(1-\alpha) \cdot \lambda \cdot v \cdot \gamma^{T}
$$


Direct substitution shows that the expression in (6) is equal to zero if and only if:

$$
(1-\alpha) \sum_{i=1}^{T} C F L_{i}^{o}\left(h_{i} \mid \theta\right) \cdot \gamma^{i}+\alpha \cdot \sum_{i=1}^{T} v \cdot d_{i} \cdot \gamma^{i}+(1-\alpha) \cdot \lambda \cdot v \cdot \gamma^{T}=0
$$

Dividing by $(1-\alpha)$ and recalling the definition of the tax factor, $\Delta$, the equality in (7) reduces to:

$$
\sum_{i=1}^{T}\left[X_{i}\left(h_{i} \mid \theta\right) \cdot p-w_{i}\left(h_{i} \mid \theta\right)-F_{i}\left(h_{i} \mid \theta\right)\right] \gamma^{i}=v \cdot \Delta .
$$

By definition $Y(\vec{h} \mid \theta)=\sum_{i=1}^{T} X_{i}\left(h_{i} \mid \theta\right) \cdot \gamma^{i}$ and therefore (8) holds if and only if $p=L C X M(\vec{h} \mid \theta)$.

With the duty cycle $\theta$ held fixed, we simplify the notation for the levelized cost of passenger miles by suppressing the dependence on $\theta$.

Claim 2. Consider two drivetrains whose levelized cost curves, $L C X M_{1}(\cdot)$ and $L C X M_{2}(\cdot)$, intersect at $\left(h^{*}, \ldots, h^{*}\right)$ with $h^{*} \in[0,8760]$. Given the daily load profile $L(t)$, the costminimizing number of baseload drivetrains, $k_{1}^{*}$, is given by:

$$
365 \cdot D\left(k_{1}^{*}\right)=h^{*}
$$

Proof: Given the load profile, $L(\cdot)$, the required total annual number of operating hours becomes:

$$
\hat{h}=365 \cdot \int_{0}^{24} L(t) d t .
$$

For any feasible fleet composition, i.e., $\left(k_{1}, k_{2}\right)$ such that $k_{2} \geq k_{+}-k_{1}$, the fleet operator will rely to the extent possible on the drivetrain with the lower unit operating cost. Specifically, the number of daily operating hours of drivetrain 1 will be:

$$
H\left(k_{1}\right) \equiv \int_{0}^{24} \min \left\{L(t), k_{1}\right\} d t
$$

The overall cost minimization problem then is to choose $k_{1}$ so as to minimize the break-even price $p$ per X-mile required to cover the fleet operator's total life-cycle cost in meeting the 
daily load profile $L(\cdot)$. In particular, $p$ must satisfy the inequality:

$$
\begin{aligned}
\sum_{i=1}^{T} p \cdot X(\hat{h}) \cdot \gamma^{i} & \geq v_{1} \cdot k_{1}+v_{2} \cdot\left(k_{+}-k_{2}\right)+\sum_{i=1}^{T}\left[3 6 5 \cdot \left(w_{1} \cdot H\left(k_{1}\right)+w_{2} \cdot\left(\hat{h}-H\left(k_{1}\right)\right)\right.\right. \\
& \left.+F_{1} \cdot k_{1}+F_{2} \cdot\left(k_{+}-k_{1}\right)+\alpha \cdot I_{i}\left(\hat{h}, k_{1}, p\right)\right] \cdot \gamma^{i} \\
& -\gamma^{T} \cdot(1-\alpha) \cdot \lambda \cdot\left(v_{1} \cdot k_{1}+v_{2} \cdot\left(k_{+}-k_{2}\right)\right) .
\end{aligned}
$$

Here $I_{i}\left(\hat{h}, k_{1}, p\right)$ denotes the taxable income in year $i$, that is:

$$
\begin{aligned}
I_{i}\left(\hat{h}, k_{1}, p\right) & \equiv p \cdot X(\hat{h})-365\left[\left(w_{1} \cdot H\left(k_{1}\right)+w_{2} \cdot\left(\hat{h}-H\left(k_{2}\right)\right)\right]\right. \\
& -F_{1} \cdot k_{1}-F_{2} \cdot\left(k_{+}-k_{1}\right)-\left[v_{1} \cdot k_{1}+v_{2} \cdot\left(k_{+}-k_{1}\right)\right] \cdot d_{i} .
\end{aligned}
$$

Recalling the definition of $\Delta$ and collecting terms, the above inequality reduces to:

$$
\begin{aligned}
p \geq & \frac{1}{\sum_{i=1}^{T} X(\hat{h}) \cdot \gamma^{i}}\left[v_{1} \cdot \Delta \cdot k_{1}+v_{2} \cdot \Delta \cdot\left(k_{+}-k_{1}\right)+\sum_{i=1}^{T}\left[3 6 5 \cdot \left(w_{1} \cdot H\left(k_{1}\right)+w_{2} \cdot\left(\hat{h}-H\left(k_{1}\right)\right)\right.\right.\right. \\
& \left.\left.+F_{1} \cdot k_{1}+F_{2} \cdot\left(k_{+}-k_{1}\right)\right] \cdot \gamma^{i}\right] .
\end{aligned}
$$

To minimize $p$, we differentiate the right-hand side of $(10)$ with respect to $k_{1}$, noting that

$$
H^{\prime}\left(k_{1}\right)=\int_{\left\{t \in[0,24] \mid L(t) \geq k_{1}\right\}} d t \equiv D\left(k_{1}\right) .
$$

This derivative is given by:

$\frac{1}{\sum_{i=1}^{T} X(\hat{h}) \cdot \gamma^{i}}\left[v_{1} \cdot \Delta+\sum_{i=1}^{T}\left[w_{1} \cdot 365 \cdot D\left(k_{1}\right)+F_{1}\right] \cdot \gamma^{i}-v_{2} \cdot \Delta-\sum_{i=1}^{T}\left[w_{2} \cdot 365 \cdot D\left(k_{1}\right)+F_{2}\right] \cdot \gamma^{i}\right]$.

For notational simplicity, we write $\operatorname{LCXM}(h)$ instead of $\operatorname{LCX} M(h, \ldots, h)$ on the domain of utilization profiles that are constant across years, i.e., $h_{i}=h$. Recalling the definition of the LCXM, the last expression for the derivative of the right-hand side of $(10)$ is proportional to:

$$
L C X M_{1}\left(365 \cdot D\left(k_{1}\right)\right)-L C X M_{2}\left(365 \cdot D\left(k_{1}\right)\right) .
$$

For a cost minimum, $k_{1}$ must be chosen so that the derivative expression in (11) is zero, which implies $k_{1}=k_{1}^{*}$, since $k_{1}^{*}$ is such that $365 \cdot D\left(k_{1}^{*}\right)=h^{*}$ and $L C X M_{1}\left(h^{*}\right)=L C X M_{2}\left(h^{*}\right)$. 
Furthermore, since $w_{2}>w_{1}$ and $D(\cdot)$ is decreasing in $k_{1}$, the objective function on the right hand-side of (10) is convex in $k_{1}$. Thus the value of $k_{1}$ that satisfies the first-order condition corresponding to (11) also yields the global cost minimum.

We note in passing that the levelized cost of the optimized fleet can be expressed as a convex combination of the two component LCXM, with the respective weights given by the respective operating hours of the two drivetrains. For simplicity, suppose that $b_{i}\left(h_{i}\right)=b$. Referring back to (10), it is then straightforward to verify that the LCXM of the optimized fleet is equal to:

$$
\begin{aligned}
\operatorname{LCXM}(365 \cdot \hat{h})= & \frac{365 \cdot H\left(k_{1}^{*}\right)}{\hat{h}} \cdot \operatorname{LCX}_{1}\left(365 \cdot H\left(k_{1}^{*}\right)\right) \\
& +\left(1-\frac{365 \cdot H\left(k_{1}^{*}\right)}{\hat{h}}\right) \cdot \operatorname{LCXM}_{2}\left(365 \cdot\left(\hat{h}-H\left(k_{1}^{*}\right)\right)\right) .
\end{aligned}
$$

Claim 3. Under the conditions of Claim 2, suppose the daily load profiles are given by $L_{j}(\cdot)$. The cost-minimizing number of baseload drivetrains, $k_{1}^{*}$, is then given by:

$$
\sum_{j=1}^{365} D_{j}\left(k_{1}^{*}\right)=h^{*}
$$

Proof: The proof of this claim mirrors that of Claim 2. The total number of vehicles acquired now becomes $k_{+}$given by the maximum value across all $L_{j}(\cdot)$. With regard to the expression in (9), the only change is that the variable operating costs now become:

$$
\sum_{i=1}^{T}\left[w_{1} \cdot \sum_{j=1}^{365} H_{j}\left(k_{1}\right)+w_{2} \cdot \sum_{j=1}^{365}\left(\hat{h}_{j}-H_{j}\left(k_{1}\right)\right)\right] \cdot \gamma^{i},
$$

where

$$
\hat{h}_{j}=\int_{0}^{24} L_{j}(t) d t \text { and } H_{j}\left(k_{1}\right) \equiv \int_{0}^{24} \min \left\{L_{j}(t), k_{1}\right\} d t .
$$

The claim then follows by proceeding exactly as in the preceding proof.

Input Usage and Cost Data. The data on input usage and cost items are furnished by various information systems at Stanford University related to energy- and fleet management. Table 2 provides average values for route-invariant cost parameters for both diesel and electric buses. The acquisition cost shown there for each bus type reflects the most recent purchase 
price. If the purchase occurred before the year 2019, we adjusted the price for inflation with an average annual inflation rate of $2.0 \%$. The capital incentive for electric buses is a subsidy granted by the California Air Resources Board under the Hybrid and Zero-Emission Truck and Bus Voucher Incentive Program 28 . The salvage value for each drivetrain is based on an estimate provided by Stanford. To assess fixed costs, we took the drivetrain-specific average across transit buses in the Marguerite fleet of annual operations and maintenance costs for the years 2017-2019. The annual fixed cost of each bus comprises the sum of registration fees, insurance cost, and components of maintenance costs that are usage-independent, as shown in Supplementary Note 2. The labor cost per hour includes the cost of the driver per hour of operation, composed of salary, benefits, and overhead. Our estimate of the fuel costs is based on the average of diesel prices per gallon paid by Stanford in 2019.

Table 2: Route-invariant cost parameters (in 2019 \$US).

\begin{tabular}{lcc}
\hline & Diesel & Electric \\
\hline Acquisition cost & $\$ 430,757$ & $\$ 750,000$ \\
Capital incentive & - & $\$ 100,000$ \\
Salvage value & $\$ 10,000$ & $\$ 38,750$ \\
Fixed cost per year & $\$ 5,054$ & $\$ 5,913$ \\
Labor cost per hour & $\$ 71.00$ & $\$ 71.00$ \\
Fueling cost per gallon & $\$ 3.40$ & - \\
Charging cost per kWh & - & $\$ 0.092$ \\
Useful lifetime & 12 years & 12 years \\
Cost of capital & $5.00 \%$ & $5.00 \%$ \\
\hline
\end{tabular}

The cost of electricity charging for EV buses deserves particular attention. Stanford purchases electricity from a variety of sources each entailing a specific set of fixed, demand and volumetric charges. The total of these electricity costs in 2019 normalized by the total volume of electricity delivered (kWh) amounts to $\$ 0.092 / \mathrm{kWh}$, which represents the average cost of electricity to the university on a volumetric basis. This cost figure is charged to all administrative units within the university for the consumption of electricity. In addition, each unit is charged a markup for various overhead cost items, resulting in a total of $\$ 0.152 / \mathrm{kWh}^{41}$. For the purpose of determining the life-cycle cost of EV buses, we only impute the normalized volumetric rate, and exclude the university-wide overhead charge, as this is the effective incremental cost per $\mathrm{kWh}$ to the university.

A time-invariant volumetric charge for electricity seems appropriate given the configura- 
tion of Stanford's energy system. While the campus as a whole is subject to demand charges and time-of-use volumetric charges, these time-dependent costs are essentially not relevant to the various operating units, including the bus depot, due to the dominance of the university's central energy facility. The facility manages the district heating and cooling for the entire campus and is, therefore, by far the largest single source of electricity demand, dwarfing, in particular, the incremental load associated with bus charging. The central energy facility has effectively the ability to ramp the university's demand for power in response to time-based price signals, thus enabling the campus to minimize both demand and time-of-use charges $\frac{42}{4}$. We note that time-invariant volumetric charges for electric buses have also been imputed in other settings applicable to university campuses and municipal bus fleets $\underline{43}$.

The variable cost components include certain maintenance and energy costs, whereby the latter is the product of the route-specific energy consumption and the fueling or charging rate provided in Table 2, Our dataset includes the variable maintenance costs and energy consumption per transit bus in the Marguerite fleet for the years 2017-2019 on the specific days these costs were incurred. These variable cost components vary by route depending on the number of stops per mile and the collection of routes served by a bus throughout the year. The number of buses assigned to each route was assumed to be constant across the years.

Table 3 provides average values for the variable cost for both drivetrains by route. Supplementary Note 2 shows which categories of the maintenance cost are considered to be usage-dependent for each drivetrain. For Route A, for instance, the average variable maintenance cost is calculated by taking the average across buses for which the annual average number of bus stops per mile is equal to that of Route A.

Route-specific energy consumption for electric and diesel drivetrains are calculated according to different methods which reflect differences in the availability of data. For electric buses, we rely on daily total net energy consumption, total time in service, and total distance traveled as provided by the battery management system (BMS) for individual buses. Net energy consumption in this context refers to the total energy provided to the bus from the battery minus the energy generated via regenerative braking. We gathered the three categories of the BMS data for electric transit buses that operated on Route A and B most frequently in 2019. To account for daily and seasonal variation, we attained for each bus a complete BMS record for a randomly selected day in each month between January-August 
2019. This produced 24 records (3 bus readings per month for 8 months) per route. The figures shown in Table 3 for electric buses represent the route-specific average of the 24 measures. The time component of this measure accounts for the actual time a bus was servicing a route. This includes in-service idling but not mid-day lulls when the bus was not in service. As a point of reference, the energy consumption per hour presented in Table 3 corresponds to a power consumption of $1.41 \mathrm{kWh} / \mathrm{mi}$ and $1.11 \mathrm{kWh} / \mathrm{mi}$ for Routes $\mathrm{A}$ and $\mathrm{B}$, respectively.

\section{Table 3: Route-specific cost parameters (in 2019 \$US).}

\begin{tabular}{lccc}
\hline & Route A & Route B & Average \\
\hline Diesel & & & \\
Variable maintenance cost per hour & $\$ 5.09$ & $\$ 8.37$ & $\$ 7.04$ \\
Energy consumption per hour (in gallons) & 6.23 & 2.48 & 4.44 \\
Fueling cost per hour & $\$ 21.16$ & $\$ 8.42$ & $\$ 15.07$ \\
Variable cost per hour & $\$ 26.25$ & $\$ 16.79$ & $\$ 22.11$ \\
Electric & & & \\
Variable maintenance cost per hour & $\$ 1.18$ & $\$ 4.46$ & $\$ 3.13$ \\
Energy consumption per hour (in kWh) & 9.13 & 3.34 & 9.01 \\
Charging cost per hour & $\$ 0.84$ & $\$ 0.31$ & $\$ 0.83$ \\
Variable cost per hour & $\$ 2.02$ & $\$ 4.77$ & $\$ 3.96$ \\
\hline
\end{tabular}

For diesel buses, we calculate energy consumption per bus by dividing the total volume (in gallons) dispensed during each refueling event to a specific bus by the total number of in-service hours of the bus within the time interval since the last refueling event for all refueling events recorded in 2019. The corresponding set of bus stops per mile for each bus is calculated based on the duty cycles performed during the same in-service time intervals. The figures in Table 3 result from taking the mean of the calculated per-bus energy consumption measures corresponding to those buses that exhibited stops per mile measures similar to Route A or Route B, windsorized at the $5.0 \%$ level. Since the refueling data includes the entire year 2019, the average consumption values account for variations across days, seasons, and vehicles. For reference, the energy consumption per hours given in Table 3 correspond to a fuel economy of 5.26 miles per gallon and 2.61 miles per gallon for Routes A and B, respectively. These values are relatively low because they account for fuel consumed during in-service idling and unplanned maintenance that require idling for troubleshooting.

Route Information. Route data for Marguerite was provided by Stanford. Table 3 provides the main route characteristics for Route A and B, as well as the simple average for 
these parameters across all routes in the system. Route data for all routes is provided in Supplementary Note 1. The number of bus stops per mile is calculated by dividing the total route distance by the number of bus stops. Finally, average velocity is determined by dividing the total route distance by the expected completion time as provided by Stanford Transportation.

Table 4: Route A, Route B and Marguerite average data.

\begin{tabular}{lccc}
\hline & Route A & Route B & Average \\
\hline Number of bus stops per mile & 1.1 & 2.7 & 1.9 \\
Average velocity (in miles per hour) & 7.4 & 3.0 & 8.7 \\
Average number of passengers & 3.2 & 9.4 & 6.9 \\
Marguerite average utilization (in hours) & 1,434 & 1,453 & 1,607 \\
\hline
\end{tabular}

In Table 3, the average number of passengers represents the number of passengers transported across the full distance of a route. This value is the average number of passengers per hour multiplied with the average passenger-miles per passenger and dividing this product by the average velocity. The number of passengers per hour, in turn, is determined by dividing the annual number of passengers that traveled a particular route by the annual total number of hours that the route was serviced. The average passenger-miles per passenger is estimated due to a lack of detailed on-boarding and off-boarding events per passenger as the expected distance in miles that the average passenger would travel on a given route. This figure is defined as the average distance between the two most popular bus stops on a route. The term popular here refers to the bus stops on a route that have the highest total number of passengers boarding over the course of a year. Given that bus routes are loops that begin and end at the same location, the average distance can be conceptualized as the average length of the two arcs that connect two points on a circle.

For the average utilization, we first calculate the operating hours of each bus in 2019 as the product of the total number of loops per route that a bus accumulated in 2019 with the expected completion time per route. Since we only have data on bus-route assignments for the year 2019, we calculate the operating hours of each bus in 2017 and 2018 by scaling the respective value for 2019 with the total miles that a bus traveled 2017 and 2018. The average utilization per route shown in Table 3 is calculated as follows: for Route B, for instance, one takes the average of all buses that have an average number of bus stops per mile equal to that of Route B. For the system average, the average utilization is the average across all 
transit buses.

The two routes A and B yield extreme findings for the range of routes operated by Marguerite, because they entail the highest and lowest average fuel consumption per hour observed for diesel buses in the data set. Other routes of the system entail values in between, with the system average amounting to 4.44 gallons per hour. This can largely be attributed to the observation that more bus stops per mile reduce the average miles per hour traveled on a route. Route A exhibits one of the highest values for average velocity, while the opposite holds for Route B. In contrast to the relatively small energy cost of electric buses, the fuel cost for diesel buses becomes the dominant factor in determining the critical utilization rate and, by implication, the cost-minimizing composition of the bus fleet (see Figure 3).

Miles Traveled as the Output Measure. The application to transit buses in Section 4 focused on the output measure of passenger-miles for the transportation service in question. Figure 4 shows the life-cycle cost curves for both electric and diesel buses on routes A and $\mathrm{B}$ as a function of miles, rather than passenger-miles, traveled. We refer to this cost curve as $\operatorname{LCM}(\cdot)$. Since $b(\cdot \mid \theta)>1$ for both routes, the generic expression for the levelized cost of X-miles shows that the $\operatorname{LCM}(\cdot)$ curve decreases more steeply than the $L C P M(\cdot)$ curve, i.e., $\left|L C P M^{\prime}(h)\right|<\left|L C M^{\prime}(h)\right|$, for all values of $h$.

We recall from Figure 1 that the $L C P M$ for both types of drivetrains decreases as one switches from Route A to Route B. Yet, the opposite change is observed for $L C P M$ in Figure 4, This opposite movement reflects that there are on average 9.4 passengers who complete Route B, while there are only 3.2 such passengers on Route A. Comparison of Figure 1 and Figure 4 also illustrates that the critical utilization rate $h^{*}$ is invariant to the measure of output. In general, we conclude that for any given drivetrain the magnitude and shape of the levelized cost curve depends on the specific measure of X-miles. However, both the life-cycle cost comparison across drivetrains, that is, the critical utilization rate $h^{*}$, and the cost minimizing composition of the vehicle fleet are invariant to the actual measure of X-miles. 

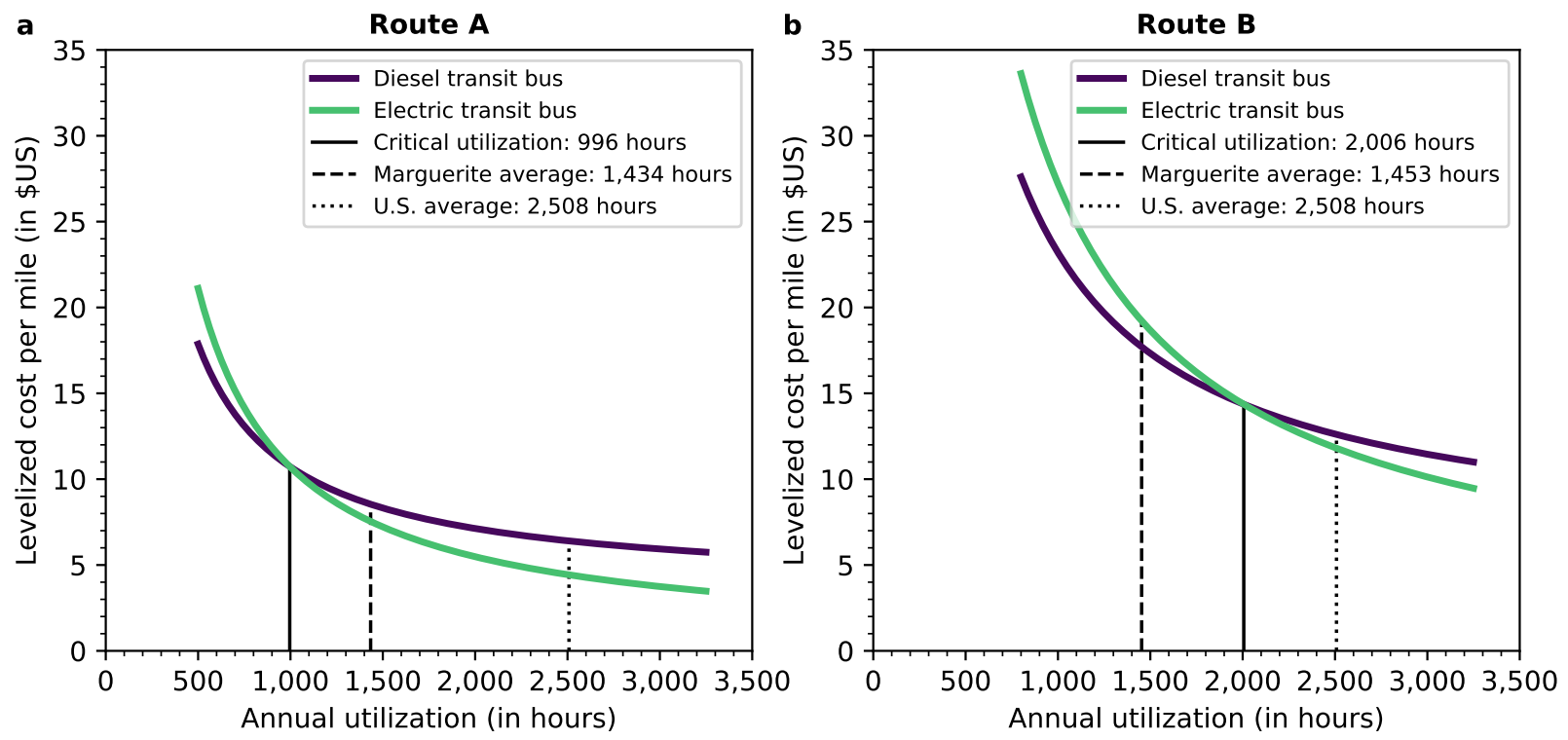

Figure 4: Levelized cost per mile. a,b, This figure shows the levelized cost per mile of diesel and electric transit buses for (a) Route A and (b) Route B.

\section{Data availability}

The data used in this study are referenced in the main body of the paper and the Supplementary Information. Additional data and information is available from the corresponding author upon reasonable request.

\section{Additional information}

Supplementary information is available for this paper at (Link when published).

\section{References}

[1] Knobloch, F. et al. Net emission reductions from electric cars and heat pumps in 59 world regions over time. Nature Sustainability 3, 437-447 (2020). URL https://doi.org/10.1038/ s41893-020-0488-7.

[2] IEA. Global EV Outlook 2019 (2019). URL https://www.oecd-ilibrary.org/content/ publication/35fb60bd-en.

[3] BNEF. Electric vehicle outlook 2019. Report, Bloomberg New Energy Finance, New York, NY (2019). 
[4] Arbib, J. \& Seba, T. Rethinking Transportation 2020-2030 (Rethink X, 2018).

[5] Needell, Z. A., McNerney, J., Chang, M. T. \& Trancik, J. E. Potential for widespread electrification of personal vehicle travel in the united states. Nature Energy 1, 16112 (2016). URL https://doi.org/10.1038/nenergy.2016.112.

[6] He, X. et al. Economic and climate benefits of electric vehicles in china, the united states, and germany. Environmental Science $\&$ Technology 53, 11013-11022 (2019). URL https: //doi.org/10.1021/acs.est.9b00531.

[7] Buonocore, J. J. et al. Metrics for the sustainable development goals: renewable energy and transportation. Palgrave Communications 5, 1-14 (2019). URL http://dx.doi.org/10. 1057/s41599-019-0336-4

[8] Liang, X. et al. Air quality and health benefits from fleet electrification in China. Nature Sustainability 2, 962-971 (2019).

[9] Plötz, P., Axsen, J., Funke, S. A. \& Gnann, T. Designing car bans for sustainable transportation. Nature Sustainability 2, 534-536 (2019). URL http://dx.doi.org/10.1038/ s41893-019-0328-9.

[10] Future passenger mobility. Nature Sustainability 3, 407 (2020).

[11] Islam, A. \& Lownes, N. When to go electric? a parallel bus fleet replacement study. Transportation Research Part D: Transport and Environment 72, 299 - 311 (2019). URL http://www.sciencedirect.com/science/article/pii/S1361920918309829.

[12] Pelletier, S., Jabali, O., Mendoza, J. E. \& Laporte, G. The electric bus fleet transition problem. Transportation Research Part C: Emerging Technologies 109, 174 - 193 (2019). URL http://www.sciencedirect.com/science/article/pii/S0968090X1930868X.

[13] Luderer, G. et al. Residual fossil CO2 emissions in $1.5-2{ }^{\circ} \mathrm{c}$ pathways. Nature Climate Change 8, 626-633 (2018). URL http://dx.doi.org/10.1038/s41558-018-0198-6.

[14] Nordhaus, W. Climate change: The ultimate challenge for economics. American Economic Review 109, 1991-2014 (2019).

[15] Lebeau, P., Macharis, C., Mierlo, J. \& Lebeau, K. Electrifying light commercial vehicles for city logistics? a total cost of ownership analysis. European Journal of Transport and Infrastructure Research 15 (2015). URL https://superheroscitech.tudelft.nl/ejtir/article/view/ 3097. 
[16] Lajunen, A. \& Lipman, T. Lifecycle cost assessment and carbon dioxide emissions of diesel, natural gas, hybrid electric, fuel cell hybrid and electric transit buses. Energy 106, 329 - 342 (2016). URL http://www.sciencedirect.com/science/article/pii/S036054421630319X.

[17] Tong, F., Hendrickson, C., Biehler, A., Jaramillo, P. \& Seki, S. Life cycle ownership cost and environmental externality of alternative fuel options for transit buses. Transportation Research Part D: Transport and Environment 57, 287 - 302 (2017). URL http://www . sciencedirect. com/science/article/pii/S136192091630476X.

[18] Cooper, R. \& Kaplan, R. R. S. Activity-Based Systems: Measuring the Costs of Resource Usage. Harvard Business Review 6, 96-103 (1992).

[19] Kaplan, R. S. \& Anderson, S. R. Time-driven activity-based costing: a simpler and more powerful path to higher profits (Harvard business press, 2007).

[20] APTA. 2019 public transportation fact book. Report 70th Edition, American Public Transportation Association, Washington DC (2019).

[21] MIT. The Future of Coal: Options for a Carbon-Constrained World. Tech. Rep. ISBN 978-0615-14092-6, Massachusetts Institute of Technology, Cambridge, MA (2007).

[22] Reichelstein, S. \& Rohlfing-Bastian, A. Levelized Product Cost: Concept and Decision Relevance. The Accounting Review 90, 1653-1682 (2015).

[23] Comello, S. \& Reichelstein, S. The emergence of cost effective battery storage. Nature Communications 10, 2038 (2019). URL http://www.nature.com/articles/s41467-019-09988-z.

[24] Feng, W. \& Figliozzi, M. An economic and technological analysis of the key factors affecting the competitiveness of electric commercial vehicles: A case study from the usa market. Transportation Research Part C: Emerging Technologies 26, 135 - 145 (2013). URL http://www.sciencedirect.com/science/article/pii/S0968090X12000897.

[25] Ansaripoor, A. H., Oliveira, F. S. \& Liret, A. Recursive expected conditional value at risk in the fleet renewal problem with alternative fuel vehicles. Transportation Research Part C: Emerging Technologies 65, 156 - 171 (2016). URL http://www.sciencedirect.com/ science/article/pii/S0968090X1500426X.

[26] Ahani, P., Arantes, A. \& Melo, S. A portfolio approach for optimal fleet replacement toward sustainable urban freight transportation. Transportation Research Part D: Transport and Environment 48, 357 - 368 (2016). URL http://www.sciencedirect.com/science/article/ pii/S1361920916301675. 
[27] Glenk, G. \& Reichelstein, S. Synergistic value in vertically integrated power-to-gas energy systems. Production and Operations Management 29, 526-546 (2020). URL https: //onlinelibrary.wiley.com/doi/abs/10.1111/poms.13116. wiley.com/doi/pdf/10.1111/poms.13116.

[28] CARB. Hybrid and Zero-Emission Truck and Bus Voucher Incentive Project (2020). URL https://www .californiahvip.org/how-to-participate/\#Eligible-Vehicle-Catalog.

[29] Schmidt, T. S. et al. Adverse effects of rising interest rates on sustainable energy transitions. Nature Sustainability 2, 879-885 (2019). URL https://doi.org/10.1038/ s41893-019-0375-2.

[30] Schmidt, O., Hawkes, A., Gambhir, A. \& Staffell, I. The future cost of electrical energy storage based on experience rates. Nature Energy 6, 17110 (2017).

[31] Schmidt, O., Melchior, S., Hawkes, A. \& Staffell, I. Projecting the future levelized cost of electricity storage technologies. Joule 3, 81 - 100 (2019). URL http://www.sciencedirect. com/science/article/pii/S254243511830583X.

[32] Jiao, N. \& Evans, S. Business Models for Repurposing a Second-Life for Retired Electric Vehicle Batteries, 323-344 (Springer International Publishing, Cham, 2018). URL https: //doi.org/10.1007/978-3-319-69950-9_13.

[33] Martinez-Laserna, E. et al. Battery second life: Hype, hope or reality? a critical review of the state of the art. Renewable and Sustainable Energy Reviews 93, 701 - 718 (2018). URL http://www.sciencedirect.com/science/article/pii/S1364032118302491.

[34] Kamargianni, M., Li, W., Matyas, M. \& Schäfer, A. A critical review of new mobility services for urban transport. Transportation Research Procedia 14, 3294 - 3303 (2016). URL http:// WWW.sciencedirect.com/science/article/pii/S2352146516302836. Transport Research Arena TRA2016.

[35] Matyas, M. \& Kamargianni, M. The potential of mobility as a service bundles as a mobility management tool. Transportation 46, 1951-1968 (2019). URL https://doi.org/10.1007/ s11116-018-9913-4.

[36] Taiebat, M. \& Xu, M. Synergies of four emerging technologies for accelerated adoption of electric vehicles: Shared mobility, wireless charging, vehicle-to-grid, and vehicle automation. Journal of Cleaner Production 230, 794 - 797 (2019). URL http://www.sciencedirect. com/science/article/pii/S0959652619316683. 
[37] Feng, W. \& Figliozzi, M. Vehicle technologies and bus fleet replacement optimization: problem properties and sensitivity analysis utilizing real-world data. Public Transport 6, 137-157 (2014). URL https://doi .org/10.1007/s12469-014-0086-z.

[38] Wadud, Z. Fully automated vehicles: A cost of ownership analysis to inform early adoption. Transportation Research Part A: Policy and Practice 101, 163 - 176 (2017). URL http: //www.sciencedirect.com/science/article/pii/S096585641630739X.

[39] Nurhadi, L., Borén, S., Ny, H. \& Larsson, T. Competitiveness and sustainability effects of cars and their business models in swedish small town regions. Journal of Cleaner Production 140, 333 - 348 (2017). URL http://www.sciencedirect.com/science/article/pii/ S0959652616303134. Systematic Leadership towards Sustainability.

[40] Chen, X. et al. Impacts of fleet types and charging modes for electric vehicles on emissions under different penetrations of wind power. Nature Energy 3, 413-421 (2018). URL https: //doi.org/10.1038/s41560-018-0133-0.

[41] Stanford University. Historical Utilities Rates - Charge Out Rates (2020). URL https: //lbre.stanford.edu/sem/historical-utilities-rates.

[42] de Chalendar, J. A., Glynn, P. W. \& Benson, S. M. City-scale decarbonization experiments with integrated energy systems. Energy and Environmental Science 12, 1695-1707 (2019). URL http://dx.doi.org/10.1039/C8EE03706J.

[43] Eudy, L., Prohaska, R., Kelly, K. \& Post, M. Foothill transit battery electric bus demonstration results. Report NREL/TP-5400-65274, National Renewable Energy Laboratory, Golden, CO (2016). 


\section{Supplementary Information}

\section{Supplementary Table 1: List of Symbols and Acronyms.}

\begin{tabular}{|c|c|c|}
\hline Variable & Unit & Description \\
\hline$\alpha$ & $\%$ & Corporate income tax rate \\
\hline$\Delta$ & - & Tax factor \\
\hline$\gamma$ & - & Discount factor \\
\hline$\lambda$ & $\%$ & Share of acquisition expenditure yielding the salvage value \\
\hline$\theta$ & - & Description of duty cycle \\
\hline$a(\theta)$ & miles/hour & Average velocity \\
\hline$b_{i}(h \mid \theta)$ & passengers or tons & Number of passengers or mass transported in year $i$ \\
\hline$B M S$ & - & Battery management system \\
\hline$c(h \mid \theta)$ & $\$ / \mathrm{X}$-mile & Levelized acquisition cost \\
\hline$C F L_{i}^{o}$ & $\$$ & Annual pre-tax cash flow in year $i$ \\
\hline$d_{t}$ & - & Depreciation Schedule \\
\hline$D(k)$ & hours & Total time during which at least $k$ vehicles must be in operation \\
\hline$f(h \mid \theta)$ & $\$ / \mathrm{X}$-mile & Levelized fixed cost \\
\hline$F_{i}(\theta$ & $\$ /$ year & Fixed operating cost in year $i$ \\
\hline$H\left(k_{i}\right)$ & hours & Number of daily operating hours of a drivetrain i \\
\hline$h_{i}$ & hours & Hours of operation in year $i$ \\
\hline$\vec{h}$ & hours & Usage profile \\
\hline$I_{i}$ & $\$ /$ year & Taxable income in year $i$ \\
\hline$k$ & - & Number of vehicles \\
\hline$L(t)$ & in $k$ & Load profile per hour $t$ \\
\hline$L C M$ & $\$ /$ mile & Levelized cost per mile \\
\hline$L C O E$ & $\$ / \mathrm{kWh}$ & Levelized cost of electricity \\
\hline$L C P M$ & $\$ /$ passenger-mile & Levelized cost per passenger-mile \\
\hline$L C X M$ & $\$ / \mathrm{X}$-mile & Levelized cost per X-mile \\
\hline$k W h$ & - & Kilowatt hour \\
\hline$p$ & $\$ / \mathrm{X}$-mile & Revenue attained per X-mile \\
\hline$r$ & $\%$ & Interest rate \\
\hline$T$ & years & Useful lifetime of a given vehicle \\
\hline$T C O$ & $\$$ & Total cost of ownership \\
\hline$v$ & $\$$ & Acquisition expenditure of the transportation vehicle \\
\hline$w_{i}(h \mid \theta)$ & $\$ /$ year & Variable operating cost in year $i$ \\
\hline$w(h \mid \theta)$ & $\$ / \mathrm{X}$-mile & Levelized variable operating cost \\
\hline$X_{i}(\vec{h} \mid \theta)$ & X-mile & Output measure, where $\mathrm{X}$ depends on $b_{i}(h \mid \theta)$ in year $i$ \\
\hline$Y(\vec{h} \mid \theta)$ & X-miles & Levelization factor \\
\hline
\end{tabular}




\section{Supplementary Table 2: General Specifications for the Examined Buses.}

\begin{tabular}{lcc}
\hline Specification & Diesel & Electric \\
\hline Make & Gillig MA & BYD K9 Electric Bus \\
Vintage (year \& number in fleet) & $2003(8)$ & $2013(1), 2014(10), 2017(18)$ \\
Gross Vehicle Weight [lbs] & 39,600 & 40,786 \\
Length [ft] & 35 & 35.8 \\
Passenger Capacity & 32 & 34 \\
Drivetrain & Cummins ISB 5.9L I6; 235hp; & AC synchronous motor; 80 kW, \\
& 460 lb-ft torque & 350 kWh iron-phosphate battery \\
\hline
\end{tabular}




\section{Supplementary Note 1. Transit Bus System Route Data.}

Route data for the Stanford Marguerite transit bus system examined, including system map and bus stop locations is found at the Stanford Transportation website:

https://transportation.stanford.edu/marguerite/view-maps-and-schedule.

Route information, including the number of bus stops per mile, the average velocity, average number of passengers per hour, and the average number of passenger-miles per passenger is provided in Supplementary Table 3. Note that actual route names found on the Stanford Transportation site have been anonymized in an effort to maintain a basic level of data security and privacy.

Supplementary Table 3: Stanford Transportation Transit Bus System Route Data.

\begin{tabular}{ccccc}
\hline Route & Stops/mile & Velocity $[\mathbf{m p h}]$ & Passenger/hour & Passenger-mile/passenger \\
\hline A & 1.1 & 7.4 & 23 & 1.0 \\
B & 2.7 & 3.0 & 40 & 0.7 \\
C & 1.4 & 8.5 & 19 & 1.2 \\
D & 0.8 & 21.2 & 20 & 2.5 \\
E & 1.2 & 10.8 & 22 & 1.5 \\
F & 1.2 & 8.9 & 14 & 3 \\
G & 1.7 & 7.2 & 55 & 1.1 \\
H & 2.0 & 7.9 & 24 & 2.5 \\
I & 2.5 & 10.9 & 50 & 1.2 \\
J & 2.7 & 8.2 & 103 & 1 \\
K & 1.7 & 6.5 & 38 & 1.2 \\
L & 1.7 & 7.9 & 24 & 2.8 \\
M & 2.5 & 8.0 & 81 & 1.2 \\
N & 2.0 & 8.0 & 31 & 1.2 \\
O & 2.7 & 8.2 & 15 & 1.2 \\
\hline
\end{tabular}




\section{Supplementary Note 2. Constituent Variable and Fixed Costs}

Stanford Transportation provided detailed operational cost data. Variable operating and fixed operating costs, are aggregations of cost subcategories provided in Supplementary Table 4. For each cost subcategory listed, its applicability is indicated per drivetrain, as well as to which operational cost, variable or fixed, it belongs. The allocation of subcategory costs to either variable or fixed was verified with respective experts at Stanford Transportation. 


\section{Supplementary Table 4: Variable and Fixed Cost Categories per Drivetrain.}

\begin{tabular}{|c|c|c|c|}
\hline Cost category & Diesel & Electric & Cost type \\
\hline HVAC & yes & yes & fixed \\
\hline Air Intake System & yes & no & fixed \\
\hline Brakes & yes & yes & variable \\
\hline Cab-Sheet Metal & yes & yes & fixed \\
\hline Charging System & yes & yes & fixed \\
\hline Clean-up/ Detailing & yes & yes & fixed \\
\hline Cooling System & yes & yes & variable \\
\hline Cranking System & yes & yes & variable \\
\hline Diesel Exhaust Fluid & yes & no & variable \\
\hline Tires & yes & yes & variable \\
\hline Dry Freight Body & yes & yes & fixed \\
\hline Electric Prop. System & no & yes & variable \\
\hline Electrical Access. & yes & yes & fixed \\
\hline Exhaust System & yes & no & variable \\
\hline Expendables & yes & yes & variable \\
\hline Frame & yes & yes & fixed \\
\hline Front Axle-Susp-Brgs & yes & yes & variable \\
\hline Fuel System & yes & no & variable \\
\hline General Accessories & yes & yes & variable \\
\hline Horn-mounting & yes & yes & fixed \\
\hline Ignition System & yes & no & fixed \\
\hline Instruments & yes & yes & fixed \\
\hline Liftgate & yes & yes & fixed \\
\hline Lighting System & yes & yes & fixed \\
\hline Lines & yes & yes & fixed \\
\hline Main Auto Trans & yes & no & variable \\
\hline Mounted Equip Repair & yes & yes & fixed \\
\hline Oil & yes & no & variable \\
\hline Power Plant & yes & yes & fixed \\
\hline Radio & yes & yes & fixed \\
\hline Rear Axle-Susp-Brgs & yes & yes & variable \\
\hline Rear Door & yes & yes & fixed \\
\hline Refrig-Mechanical & yes & yes & variable \\
\hline Satellite/Veh Comm & yes & yes & fixed \\
\hline Special & yes & yes & fixed \\
\hline Steering & yes & yes & variable \\
\hline Suppl Info Devices & yes & yes & fixed \\
\hline Towing & yes & yes & variable \\
\hline Trim & yes & yes & fixed \\
\hline Valves & yes & yes & variable \\
\hline Wash & yes & no & fixed \\
\hline Wheels-Rims-Hubs & yes & yes & variable \\
\hline
\end{tabular}

